\title{
CLASSIFICATIONS FOR PLANIMETRIC EFFICIENCY OF NURSING UNIT FLOORS
}

\author{
Zehra Tuğçe KAZANASMAZ, Gökmen TAYFUR
}

Received: 02.07.2009. Final Text: 04.01.2012

Keywords: fuzzy logic; planimetric efficiency; nursing unit floors; hospitals; architecture.
This trial study was conducted to determine classifications for planimetric design efficiency of sample public hospitals in Turkey by developing a fuzzy logic algorithm. Utilizing primary areas and circulation areas from nursing unit floor plans, the study employed triangular membership functions for the fuzzy subsets; Mamdani rule system; min operation for finding rule firing strength; max composition; and 'centroid' method for defuzzification. The input variables -primary areas per bed and circulation areas per bed- were fuzzified in this model. The relations between input variables and output variable of design efficiency were displayed as a result of fuzzy rules. To test existing nursing unit floors, efficiency output values were obtained and efficiency classes were constructed by this model in accordance with general norms, guidelines and previous studies. The classification of efficiency was resulted satisfactorily in terms of comparing hospitals. Of the fifteen hospital floor plans tested in the model, six were in a class of low efficiency, other nine were in a class of medium one. None of them were in overall agreement with the spatial requirements in regard to standards and current recommendations. The utility of this model is in the capability to indicate boundaries of efficiency classes. Hospital designers and managers may obtain feedback information from evaluations and comparisons of existing buildings. Consequently, they may benefit from this model in decision making processes.

\section{INTRODUCTION}

The primary determinant of architectural form and character in hospital buildings is the nursing unit floors and their planimetric disposition (Bobrow and Thomas, 2000; Catananti, 1998; Chand, 2002; Cox and Graves, 1981; Kim, 2001). It is also well known that the efficiency of a nursing unit is the key factor in the choice of any designed plan shape over another (such as single-corridor, double-corridor, circular shaped, square shaped 
design) together with its size (Bobrow and Thomas, 2000; Chaudhury et.al., 2003; Miller and Swensson, 2005).

It is being self evident that creating the most possible efficient nursing unit floor plan needs a detailed analysis of the best possible floor size and the choice among plans. It was considered that the former realized in the existing hospital buildings would be a trial step as to be an assessment of the degree, irrespective of their design types. To support this, an investigation was constructed for certain public hospitals in Turkey to classify the planimetric design efficiency of their nursing floors.

With regard to inpatient areas, among factors that require particular consideration in achieving a given level of design efficiency are those such as the sizes of patient rooms, their location and arrangement on the nursing floor and the placement of patient beds in these, since they determine not only the shape of the nursing floor but also influence travel distances among as well as within rooms. Dimensions of patient rooms are significant in terms of allowing, or inhibiting, ease of movement for nurses around patient beds. Further, they influence not only the dimensions of any adjacent spaces which may have to share the same wall but also the total surface area exposed to the external environment.

Even though several studies related to floor plan analysis, single-versusmultiple patient rooms and design efficiency in hospitals (Chaudhury et.al., 2003; Hardy and Lammers, 1986; Voordt et.al., 1997) have practical solutions on this subject, most of them proposed these solutions for nursing floor operational efficiency and cost-related-constructional efficiency among types. They constructed a conceptual approach to analyze spatial configurations in nursing unit floors. Another study (Kazanasmaz, 2005) dealt with certain ratios derived from nursing floor areas calculated as efficiency indicators. Kazanasmaz (2009) applied such indicators to investigate the impact of architectural configuration on hazardous residential buildings. However, such indicators were not applicable to classify efficiency of hospitals in regard to their inpatient departments.

In this study, however, an intelligence method, named fuzzy logic algorithm was developed to conduct the assessment of efficiency concern for nursing unit floor designs. This is a new alternative technique developed in recent years in the modelling of several research processes for various engineering fields including research in power plants, data mining, image processing, industrial and control applications, automotive applications, and system architecture (Sen, 1998; Sivanandam et al., 2007). Akkurt et al. (2004) in the field of mechanical engineering applied fuzzy logic model to predict cement compressive strength which resulted satisfactorily in comparison with the measured data. Saltan et al. (2007) used the model in determining the structural capacity of the flexible pavements. Results were also applicable in the field of civil engineering when compared with those obtained by other methods (linear elastic theory and finite element method). In another example, Tayfur et al. (2003) developed the fuzzy model to predict sediment loads from bare soil surfaces in the field of hydrological engineering. In that study it was concluded that predicted values were satisfactorily in agreement with the measured data. Tayfur (2006) also estimated the longitudinal dispersion coefficient in natural streams by the fuzzy model with the highest accurate rate. Although two studies offered this method in the field of architecture, there was no real evidence in literature for its common use in architecture. Çiftcioğlu (2003) employed a model to predict design quality by using 
qualitative data, while Vakili-Ardebili and Boussabaine (2007) developed an assessment framework for building design eco-efficiency which would be used in practical design decision processes.

In recent and ongoing research, it is expected that new architectural design trends will be offered for the planimetric configuration of nursing floors which is related to their physical attributes. Overall size and dimensions of inner spaces, on the other hand, are just as important to consider how to determine overall efficiency by providing sufficient areas for patients. It is basically related with certain health care facility construction standards to satisfy for patient comfort and ease of nursing operations. In this study it is necessary to assume factors of design efficiency such as spatial quality, planimetric configurations and cost related items are in accordance with whatever hospital design norms are. In other words, by developing a fuzzy logic model, it would be possible to form efficiency classes for hospitals and to classify planimetric efficiency for existing ones and to offer a new methodology for the assessment of buildings in the architectural research processes.

Researchers would be aware of this model as the utilization of fuzzy logic model has not been very common in architecture and then apply this model in building evaluation processes. Even they might expand it with the inclusion of more spatial requirements and environmental aspects to determine boundaries of total efficient design not only for hospitals but also for other building types. On the other hand, hospital designers would benefit from this method by using it as a design performance tool to aid briefing through their design process. They might get feedback information from evaluations and comparisons of existing hospitals -in terms of their efficiency class- through the application of this model. Such information would assist in practical decision making processes which lead to better design assumptions and solutions. Thus, managers and consultants together with designers would be informed and be aware of the degree of the hospitals' efficiency for other decision making processes. For example, they might decide whether to renovate nursing unit floors or not according to current standards or how to adapt existing hospitals in regard to recent technological and organizational developments.

The primary purpose of this research is to explore the possibility of utilizing fuzzy logic algorithms to more reliably defining planimetric efficiency. In relation to this, it defines a basic area analysis of nursing floor in hospital inpatient departments with respect to their planimetric design efficiency. The study finally constructs a classification of existing hospital buildings. This is taken to be a significant research of not only their intrinsic constructional and in-use operational costs but also of their potential flexibility under new architectural design trends. It is also thought that by providing much-needed feedback, the findings of this analysis -confined to samples from public hospitals in Turkey though it is- would be of benefit to such designers as may be seeking better solutions in this respect. The latent aim of this study is therefore to offer a guide to future researchers in the field of architecture by way of the approach used in its implementation. Accordingly, the specific objectives of this study can be summarizes as: 
1. To determine net usable and gross building areas of nursing unit floors, specifically, areas with functional distinctions;

2. To determine floor-area ratios as analogue indicators for measuring design efficiency;

3. To construct a fuzzy logic model to form classes for design efficiency; and

4. To classify the efficiency of existing floors by using this model with determining a certain degree of their efficiency.

\section{NURSING UNIT EVOLUTION}

The evolution of nursing units, of those being the core of the hospitals, has corresponded the demands of the period in which they were designed and constructed. Nursing units shaped the form and character of the hospitals. The construction methods and limits basically determined the form and patterns of the earliest nursing unit designs. They included factors such as,

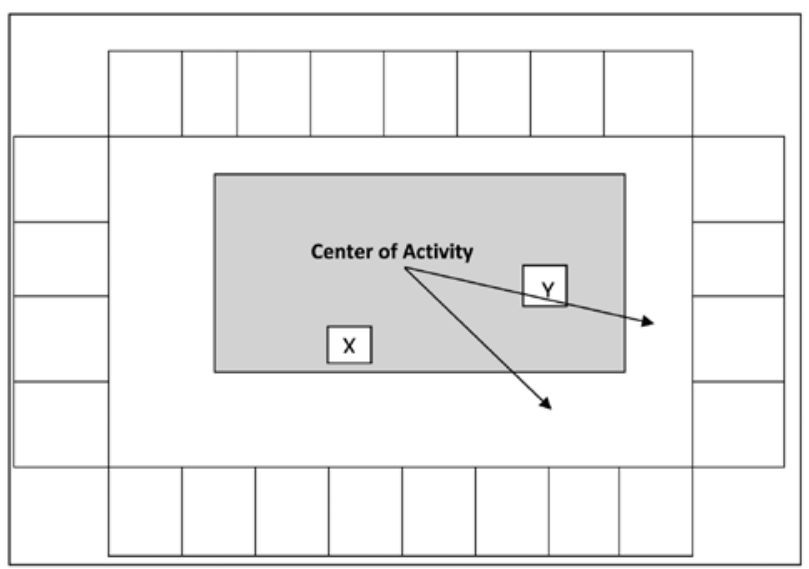

\begin{tabular}{|l|l|}
\hline Number of Beds per Floor & 24 \\
\hline Number of Beds per Cluster & 6 \\
\hline Shortest Distance from Centre (x) & $29 \mathrm{ft}$ \\
\hline Greatest Distance from Centre (y) & $60 \mathrm{ft}$ \\
\hline Total Corridor Length & $304 \mathrm{ft}$ \\
\hline Perimeter Length & $336 \mathrm{ft}$ \\
\hline Total Area & $12,993 \mathrm{sq} \mathrm{ft}$ \\
\hline Centre Support Area & $3,840 \mathrm{sq} \mathrm{ft}$ \\
\hline Available Bed Area & $6,720 \mathrm{sq} \mathrm{ft}$ \\
\hline Corridor Area & $2,432 \mathrm{sq} \mathrm{ft}$ \\
\hline Percent of Support Area & $29 \%$ \\
\hline Perimeter to Total Area & $1: 38$ \\
\hline Total Area /Number of Beds & $360 \mathrm{sq} \mathrm{ft}$ \\
\hline Distance to Bed Factor & 19 \\
\hline
\end{tabular}


available maximum structural span to house more patients and demands for natural ventilation to avoid contagious diseases. The introduction of certain technological advances affected hospital design; the use of steel structure allowed long span constructions; the use of elevators connected nursing units at the same location through a vertical route; and the use of air-conditioning let these units independent of natural ventilation. Thus nursing areas could be situated at locations without natural air. All these developments created more efficient nursing units to satisfy functional and organizational demands. Nursing care, which developed rapidly due to the increased use of hospitals, forced operational efficiency demands with the functional units as well. Several studies were conducted about nursing unit efficiency and assessment of their design starting from the late 1950s until now. First, John Thompson and Robert Pelletier of the School of Public Health at Yale University offered "Yale Traffic Index" to study traffic patterns in existing hospitals. Second, Jan Koumans of the Netherlands proposed the limitations of this survey in another study that a constant frequency should be satisfied in analyzing the distance between the patient room and the service room. Third, Delon and Smalley at Georgia Institute of Technology and the Medical College of Georgia, included financial factors such as cost of employee travel time and prorated cost of construction in their study together with the frequency of the travel in a hospital. Finally, Medical Planning Associates (MPA) and Bobrow/ Thomas and Associates (BTA) developed another simple method for the travel characteristics in a nursing unit design (Figure 1). They proposed an indicator called "the distance-to-bed-factor" which is "simply a summation of distances from nursing work centers to beds divided by the number of beds, and which serves as a proxy for more complex modeling" (Bobrow and Thomas, 2000, 138).

The single care rooms then became predominant against multi-bed rooms because of their efficiency to accommodate patients due to some incompatibilities and the need for patients' privacy and comfort. Thomas and Harvey in the Medical Planning Associates, Malibu, California, confirmed that single rooms avoided problems derived from the incompatibility factors such as age, sex, disease type or smoking. In addition while hospitals designed with only single rooms provided $95 \%$ occupancy, others with multi-bed rooms could not achieve an occupancy rate of $85 \%$. A certain patient population could accommodate in fewer rooms in a hospital designed with only single rooms, when compared with others including multi-bed rooms. Thus hospital managers could benefit from managing and operating single rooms (Bobrow and Thomas, 2000; Chaudhury, 2003).

The Yale Traffic Index developed by Thompson and Pelletier established the more dominant impact of design on the efficiency of nursing units than that of the unit size (Bobrow and Thomas, 2000). For example, location of nurse station is a crucial factor in maximizing efficiency. In the reference book, Hospitals Design and Development, by James and TattonBrown (1986), a chart is prepared to depict the average travel distance "the nurse to the bed" for each example design. It is obvious that radial units and cluster designs are to be close to Florence Nightingale's travel distance (Table 1). To reduce the travel distance, the number of nursing stations may be increased, but managers should be aware of its impact on operational and organizational aspects. 
Table 1. A chart for average travel distance (James and Tatton-Brown, 1986).

\begin{tabular}{|l|l|l|}
\hline Example & Type & $\begin{array}{l}\text { Average Distance } \\
\text { Nurse-bed (m) }\end{array}$ \\
\hline St Thomas, UK 1870 & Open & 9.30 \\
\hline Grantham, UK 1982 & Open & 9.80 \\
\hline Varburg, Sweden 1978 & Corridor & 22.40 \\
\hline Airedale, UK 1963 & Corridor & 18.40 \\
\hline Holy Cross, USA 1963 & Racetrack & 16.50 \\
\hline Gelsenkirchen, Germany 1977 & Racetrack & 15.30 \\
\hline Hvdenre, Denmark & Courtyard & 26.50 \\
\hline West Suffolk, UK 1972 & Courtyard & 19.30 \\
\hline Newham, UK 1982 & Cruciform & 11.50 \\
\hline S. Western RHA, UK 1983 & Cruciform & 9.80 \\
\hline Jegensdorf, Switzerland 1978 & Radial & 10.40 \\
\hline Nordenhamd, Germany 1974 & Radial & 9.30 \\
\hline
\end{tabular}

According to Tradewell (1993), designers will benefit from the information about the desired performance criteria (the desired efficiency) for nursing unit sizes, room types and travel distances. The hospital contributors or managers also expressed some other considerations such as location of support spaces, demands of staff and communications.

Recently, the efficiency of a nursing unit is not the only factor nor is it the key factor in the choice of any designed plan shape over another. When patient comfort and patient-focused care becomes important, patient room may need a work area for clinical treatment and care, seating area for visitors, furniture to house TV/VCR and personal belongings, personal care, maintenance and accessible bathrooms. These recent approaches made single rooms to emerge against the open ward designs (Miller and Swensson, 2005).

On the other hand, the current concerns for the hospital planning and design introduced in recent period are more than the issue of efficient hospital plan. Design quality in hospitals, for example, enhances the patients' treatment, in other words, the healing process. Thus, environmental concerns and aesthetics have become integrated with the considerations of the hospital design and construction. The use of new materials, combinations of daylight, electrical light and colour improved the environment. "It [the design] must also embrace functionality, providing an environment that enables effective and efficient healthcare to be delivered in a building that performs well, technically" (Millman and Smith, 2003). As the current focus in healthcare design is on patients and their family, good architecture may provide a high quality care with and supportive impact on user satisfaction. It offers various materials, colours, finishes with good quality and orientation to natural light as patients need (Kobus, 2000).

\section{OVERVIEW OF FUZZY LOGIC ALGORITHM}

A general fuzzy system has basically four components; fuzzification, fuzzy rule base, fuzzy output engine, and defuzzification (Figure 2). Fuzzification converts each piece of input data to degrees of membership by a look-up in one or more several membership functions. The key idea in fuzzy logic, in fact, is the allowance of partial belongings of any object to different 
Figure 2. Schematic Representation of FL System.

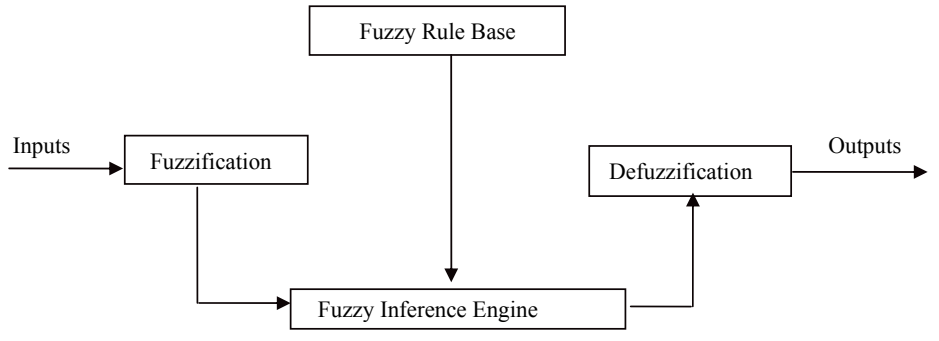

subsets of universal set instead of belonging to a single set completely. Partial belonging to a set can be described numerically by a membership function, which assumes values between 0 and 1 inclusive. Intuition, inference, rank ordering, angular fuzzy sets, neural networks, genetic algorithms, and inductive reasoning can be, among many, ways to assign membership values or functions to fuzzy variables. The intuitive approach is used rather commonly because it is simple and derived from the innate intelligence and understanding of human beings. Fuzzy membership functions may take many forms, but in practical applications simple linear functions, such as triangular ones, are preferable.

The fuzzy rule base contains rules that include all possible fuzzy relations between inputs and outputs. These rules are expressed in the IF-THEN format. In the fuzzy approach, there are no mathematical equations and model parameters. All the uncertainties, non-linear relationships, or model complications are included in the descriptive fuzzy inference procedure in the form of IF-THEN statements. There are basically two types of rule system, namely Mamdani and Sugeno (Jantzen 1999). Depending upon a problem under consideration a user can choose the appropriate rule system. According to the Sugeno rule system, the consequent part of the fuzzy rule is expressed as a mathematical function of the input variable and such a system is more appropriate for neuro-fuzzy systems (Sen 1998; 1999; Jantzen 1999). In Mamdani rule system, however, the consequent part of the fuzzy rule is also expressed as verbally. Mamadani rule construction methodology is given elsewhere (Tayfur 2006).

The fuzzy inference engine takes into account all the fuzzy rules in the fuzzy rule base and learns how to transform a set of inputs to corresponding outputs. To do so, it uses either min or prod activation operators. The activation of a rule is the deduction of the conclusion, possibly reduced by its firing strength. The prod activation (multiplication) scales the membership curves, thus preserving the initial shape, rather than clipping them as the min activation does. Jantzen (1999) points out that both methods, in general, work well. In order to illustrate the inferencing methodology, let us consider a simple case presented in Figure 3, where there are two input variables of $X$ and $Y$ (Figure $3 \mathbf{a}, \mathbf{3 b}$ ) and one output variable of $Z$ (Figure 3c). For this simple system, let us also assume the following fuzzy rules:

IF $X$ is low and $Y$ is low THEN $Z$ is high

IF $X$ is high and $Y$ is high THEN $Z$ is low

Now, let us see how the inference engine would produce fuzzy outputs for a given input vector of $X$ is 20 and $Y$ is 30. As seen in Figure 3a, $X=20$ is a part of 'low' and 'high' subsets with different degrees of membership of 
(a)

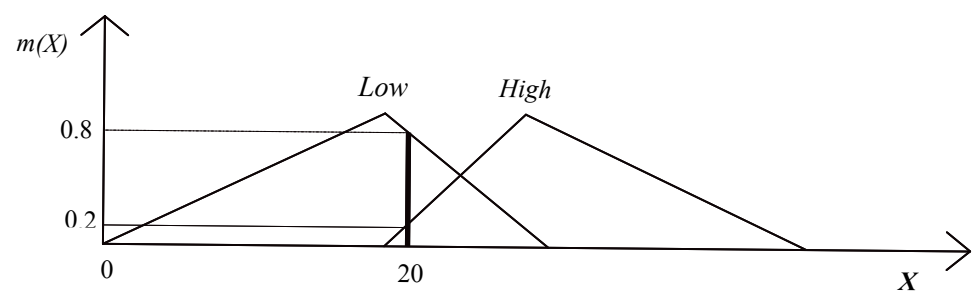

(b)

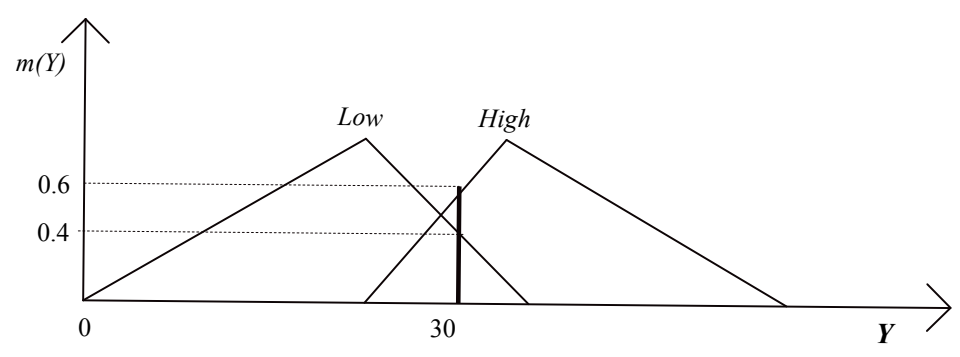

(c)

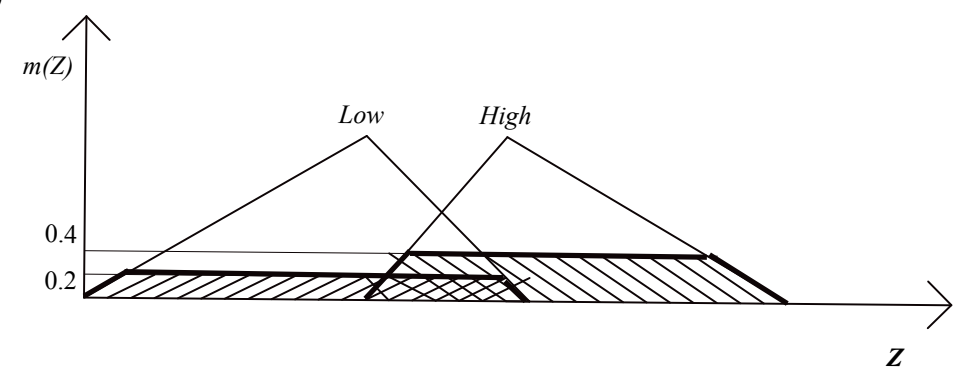

Figure 3. Schematic Representation of Fuzzy Inferencing (a) $X=20$; (b) $Y=30$; (c) Fuzzy Output Sets for $Z$.

0.8 and 0.2 , respectively. Similarly, $Y=30$ is part of 'low' and 'high' subsets with 0.4 and 0.6 degrees of membership, respectively (Figure $3 \mathbf{b}$ ). Fuzzy inference engine will consider the above rules and by min activation find the fuzzy output set of ' $h i g h$ ' from the first rule with 0.4 firing strength (this value would be 0.32 by prod activation) and output set of 'low' from the second rule with 0.2 firing strength (this value would be 0.12 by prod activation)(Figure 3c). Note that inferencing produces not a crisp output value but assigns whole fuzzy output subsets to the output variable (see, shaded areas in Figure 3c). The next subprocess in inferencing is the composition subprocess where all of the fuzzy subsets assigned to output variable are combined together to form a single subset for the output variable. For this purpose, there are basically two composition methods-maximization (max) and summation (sum). In max composition, the combined output fuzzy subset is constructed by taking the point-wise maximum over all of the fuzzy subsets assigned to the output variable by the inference rule. In sum composition, the combined output fuzzy subset 
Figure 4. Schematic Representation of (a) max Composition and BOA Defuzzification $\left(z^{*}\right.$ halves the whole set) (b) sum Composition and COG Defuzzification $\left(z^{*}\right.$ is the abscissa under the center of gravity of the whole set). (a)

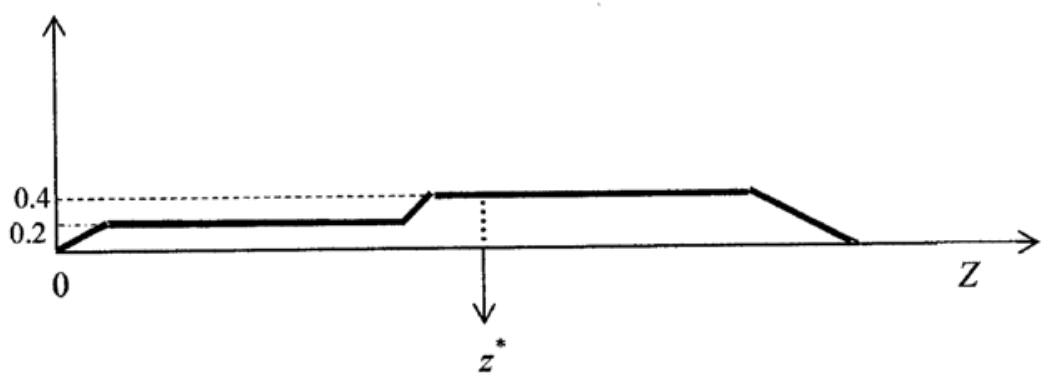

(b)

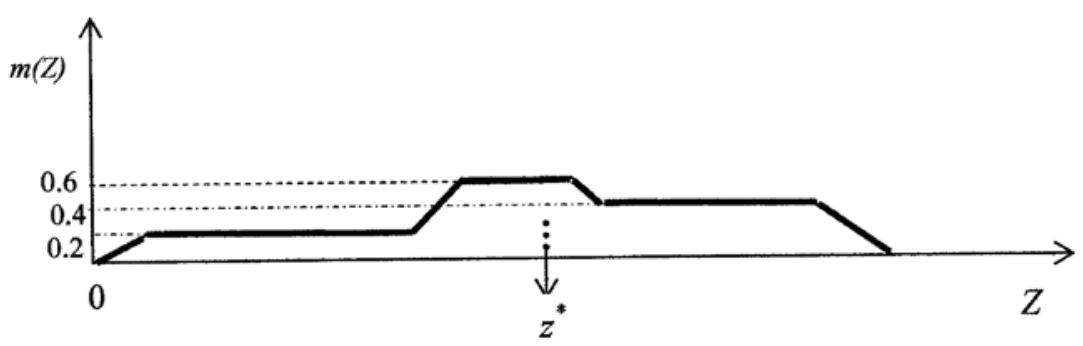

is constructed by taking the point-wise sum over all of the fuzzy subsets. Consequently, in sum composition it is sometimes possible to obtain truth values greater than one. Note that sum composition must be followed by the centre of gravity (COG) defuzzification method (Jantzen 1999). Figure $4 a, 4 b$ present combined fuzzy output subsets derived by the max and sum compositions for the above example, respectively.

Defuzzification converts the resulting fuzzy outputs from the fuzzy inference engine to a number. There are many defuzzification methods, such as centre of gravity (COG), bisector of area (BOA), mean of maxima $(\mathrm{MOM})$, leftmost maximum (LM), and rightmost maximum (RM), etc. (Jantzen 1999; Sen 1999). The MOM, LM and RM methods disregard the shape of the fuzzy set and hence, they are employed in particular problems (Jantzen 1999). BOA method picks the abscissa of the vertical line that divides the area of the combined output fuzzy subset in two equal halves (Figure 4a). In centroid (COG) method the crisp output value is the abscissa under the centre of gravity of the combined output fuzzy subset (Figure $4 \mathrm{~b}$ ). The centroid (COG) method is the most commonly used defuzzification method and for the discrete case it is expressed as (Jantzen, 1999):

$$
z^{*}=\frac{\sum_{i} i\left(z_{i}\right) z_{i}}{\sum_{i} i\left(z_{i}\right)}
$$

where $z^{*}=$ defuzzified output value. $z_{i}=$ output value in the $i^{\text {th }}$ subset; and $\mu\left(z_{i}\right)=$ membership value of the output value in the $i^{\text {th }}$ subset. For the continuous case, the summations in (1) are replaced by the integrals.

The details of FL algorithm are available in the literature (Jantzen, 1999; Sen, 1998). 


\section{MATERIAL}

Subject matter was defined to be healthcare facilities nominally in the public domain. To allow of as broad diversity as possible, no further discrimination was made in the study domain regarding their specialization, if any.

The study material itself consisted of nursing unit floor plan drawings, as obtained from the Department of Works, Ministry of Public Works and Settlement and the Department of Construction and Real Properties of the Directorate-General for Health Services within the Social Security Administration. As were selected 15 facilities, comprised of three basic plan types; namely, single-loaded corridor and double-loaded corridor with and without courtyard, an alpha-numeric identity code, S01 to S15, was randomly assigned each sample element to keep track of operations. Their origins ranged from those based on architectural competition, those based on commissions from the administrative authority and those based on standard Ministry designs while their finalization dates ranged from 1970 to 2002 .

As the investigation proper was specifically delimited to the planimetric design efficiency analysis of nursing facilities, only typical floor plans pertaining to these facilities were actually used.

Areas calculated from these were:

Net usable floor area: This was the area of all interior spaces on a typical nursing floor as calculated from the internal (wall-face-to-wall-face) dimensions given on floor plans. Excluded were door thresholds, balconies, terraces, ventilation and/or utilities ductways and/or shafts, light wells, elevator shafts and similar thru-floor cavities; the elements of structure, such as columns and piers, were also excluded. It was on the assumption that the larger this area per bed, the stronger would be the perception of an overall institutional outlook that provided patient comfort, well-being and care (Hardy and Lammers, 1986).

Gross floor area: This comprised the overall built area of a typical nursing floor, calculated from the external dimensions given on floor plans. Again excluded were all unenclosed projections from wall faces, such as solar control overhangs and fins, balconies, terraces, catwalks, etc., as well as projections of attached columns.

Derived from pertinent nursing floor plan drawings on the basis of dimensions given thereon were raw data as utilized in calculating the various floor areas deemed of relevance to the study. Also utilized were the room and / or space designations given thereon, which helped establish a basic functional distinction, as described below, among the various types occupying a given floor.

As the basic purpose of the nursing facility is the treatment and recuperation of patients, all rooms and spaces thereon were classified into three categories on the basis of whether they were to be considered as "served" spaces, as "servant" spaces, or as those simply providing means of access to and/or among these. This was done in reference to the designations ascribed to individual rooms/spaces on the floor plans. Categories were re-named so that those in the first category were designated as 'primary spaces'; those in the second, as 'secondary spaces'; and those in the third, as 'circulation spaces'. 


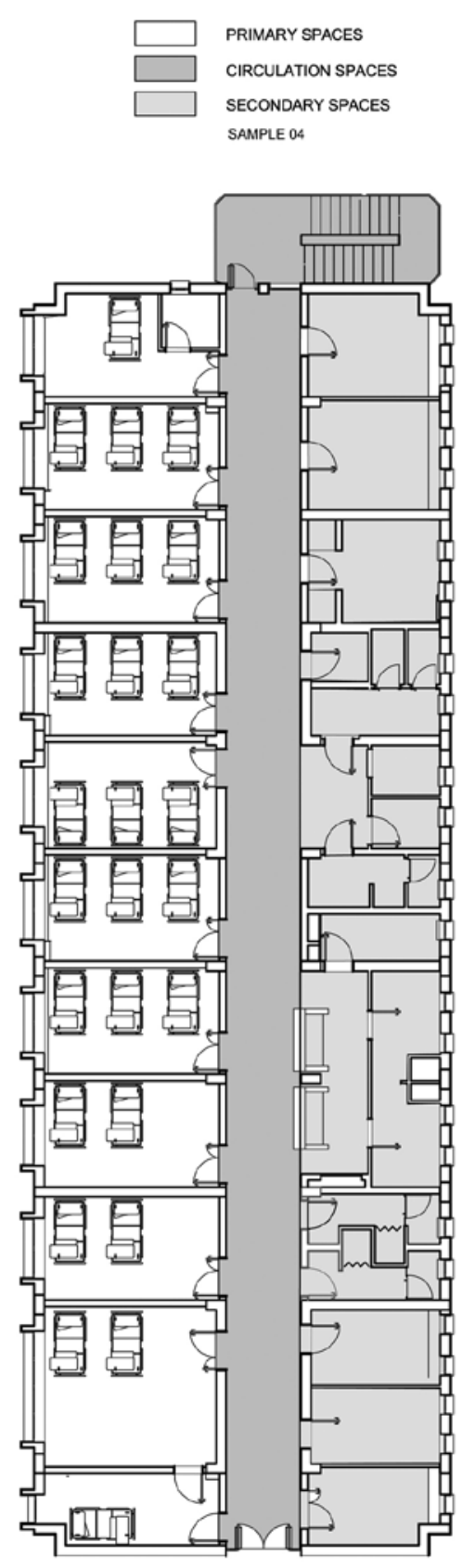

Figure 5. A schematic drawing of a nursing floor showing primary, secondary and circulation areas.
The coverage of each was briefly as described below:

Primary spaces: In this category were included all patient facilitiesbedrooms (both single- and multi-patient types), and isolation rooms. Ensuite bathrooms / toilets within patient chambers were also counted in this category.

Secondary spaces: To this category were assigned all other facilities excepting what were counted as circulation spaces, so that it was inclusive of common patient toilets and bathrooms, doctor and nurse quarters, examination rooms, clean and soiled linen rooms, mechanical and electrical rooms, storerooms for medical supplies and equipment, nurses' stations, visitor waiting rooms and any other spaces for support services specific to the type of hospital in the sample.

Circulation spaces: Comprised of all spaces not otherwise designated, this category thus included all lobbies and hallways; as well as all service and main access corridors. An example of a floor plan delineating these spaces is presented in Figure 5.

From calculated areas and ancillary data on capacity were obtained ratios relevant to patient spaces, considered to be analogue indicators of design efficiency, while their justifications are iterated as the following:

Area of primary spaces per bed: Distinct from net usable area per bed, this was taken as a direct indicator of the priority values attached to the provision of adequate patient accommodation in the overall space allocation scheme, again on the assumption that the larger it was, the greater would have been the adjunct priority.

Current US and UK recommendations (The American Institute of Architects, 1997; NHS Estates, 2005) for the maximum primary area per bed are almost $20 \mathrm{~m} 2$. Room size is as important as space around the bed, the ergonomic envelope. Room size has increased to accommodate numerous equipment and to provide immediate access to all sides of the patient. It has been established that most activities carried out at the bedside can be accommodated within dimensions $3,600 \mathrm{~mm}$ width $\times 3,700 \mathrm{~mm}$ depth. This represents the clear space around the bed, with a size of 2,235 $\mathrm{mm} \times 1,000$ $\mathrm{mm}$; and does not include space for storage, preparation and worktops. In addition there is the wc/wash basin/shower (4.5m2) and clinical workstation, storage and overnight stay facility (up to 3.0m2).

Key factors influencing space around the bed include privacy and dignity, patient acuity, length of hospital stay, age and functional capacity, patient mobility- as therapeutic activity, clinical treatment, and risks associated with lifting patients, infection control, family support and visiting, accessibility for staff. Robert Feeney Associates 2004 have carried out studies of bedside manoeuvring and transfer space at Leeds General Infirmary, and at Loughborough University where mock-up bed space was located (NHS Estates, 2005).

Area of circulation spaces per bed: The outlook here was straightforward in that the ratio would inherently reflect not only the anticipated traffic density in terms of both patient and staff movement, but also the priority given to obtaining an efficient design in terms of particular floor arrangement preferences so implemented while keeping to any normative requirements that may have been in effect. Although there was no real evidence in literature for square meter standards of circulation areas, recommendations for efficient and cost effective building and space 
planning which derive from design practice and from the data collection of completed construction projects indicate that $10-30 \%$ of the total floor area is dedicated to the circulation space. Hospital planners or designers, therefore, seek to minimise circulation space (NHS Estates 2005). Optimum circulation sizes also are highly related with the choice among plan types, and the layout of patient rooms. In addition, minimum corridor widths are to be 2,500 meters to provide sufficient space e.g. for people passing, moving King Fund beds, which are 2,235 meters long and 1,000 meters wide, trolleys, hoists and so on (Neufert, 2002).

\section{METHOD}

The study was designed and constructed in accordance with due fuzzy logic algorithm. By following certain norms and previous studies related to nursing unit areas, a fuzzy logic model was developed, and existing nursing floors' efficiency was classified according to this model.

\section{DATA COMPILATION}

As the first step in the compilation procedure, data sheets were designed to record the various quantitative and descriptive features derived from the material for each sample element. Thus recorded were room/space designations, both as given and as categorized by the author; the various measurements, areas and ratios cited in the previous section, dates of design commissioning and completion and the type of nursing floor organization.

\section{FUZZY MODEL CONSTRUCTION}

A fuzzy model was constructed by taking standard space requirements for patient areas mentioned in guidelines for the design of healthcare facilities (NHS Estates 2005), and a previous research data of circulation areas by Bobrow and Thomas (2000). The fuzzy rules were constructed by expert opinion and the data set ascribed in the sample. The MATLAB Version 6.5 software program was used in constructing the model. Primary area per bed and circulation area per bed and efficiency were fuzzified in fuzzy subsets in order to cover the degree of design efficiency of nursing floors. The maximum primary area per bed is considered as $20 \mathrm{~m}^{2}$ and its subdivision into three subsets as low (L), medium $(\mathrm{M})$, and high $(\mathrm{H})$ is considered to have triangular membership functions as presented in Figure 6a. Similarly, circulation area per bed is considered to have a maximum value of $4 \mathrm{~m} 2$ and its subdivision into three subsets as low (L), medium $(\mathrm{M})$, and high $(\mathrm{H})$ is considered to have triangular membership functions as presented in Figure $\mathbf{6 b}$. Finally, efficiency is considered to have a maximum value of 1 and its subdivision into three subsets as $L, M$, and $H$ is considered to have triangular membership functions as represented in Figure 6c.

Subdivisions of the primary area per bed (Figure 6a) and circulation area per bed (Figure 6b) can be considered valid for most cases in a broad sense. They were not defined arbitrarily but dependable by expert opinion. Similarly, the subsets of fuzzy changes in efficiency, which resemble values of relevant guidelines and norms, present basic classifications which can be applied for any type of nursing unit floors.

The fuzzy rule base, presenting relations between input variables -primary area per bed and circulation area per bed- and output variable (efficiency), was then constructed. Fuzzy rules, in this study, were inferred from the 
Figure 6. Fuzzy subsets for (a) primary area per bed (b) circulation area per bed (c) efficiency.
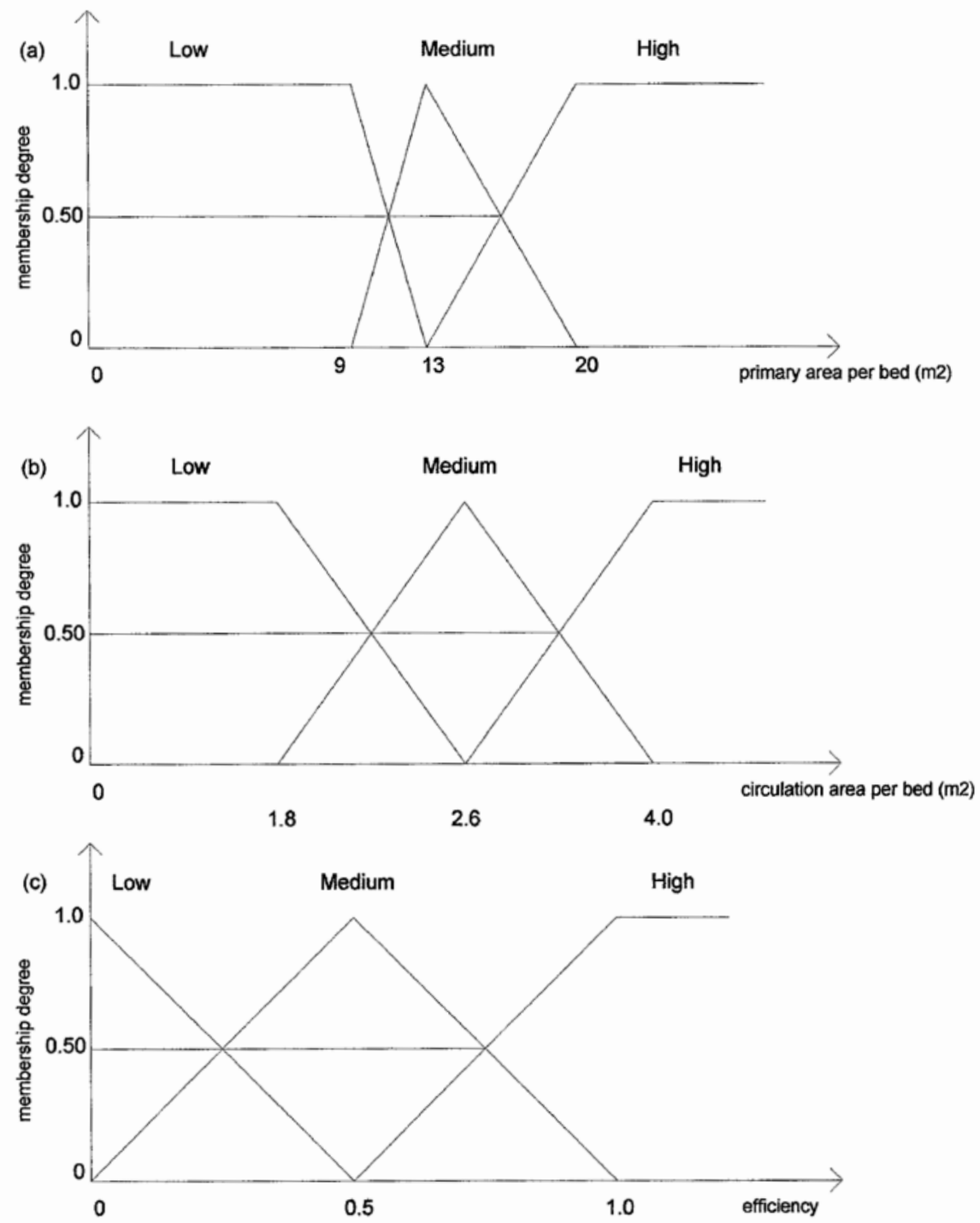

general knowledge in literature (The American Institute of Architects, 1997; Hardy and Lammers, 1986; Catananti, 1998; NHS Estates 2005). This study employed the commonly used Mamdani rule system. The antecedent part of the rule, the part starting with IF, up to THEN, included a statement on primary area per bed and circulation area per bed while the consequent part, part starting with THEN, up to the end, included a statement on efficiency concern. For example,

'IF the primary area per bed is 'Low', and the circulation area per bed is 'Low',

THEN the efficiency is 'Low'

These rules constructed in this study for design efficiency of nursing unit floors in hospitals are summarized in Table2. These rules might be considered as valid for the classification of efficiency, since they followed simple guides based on expert opinion mentioned in literature on the structure of the fuzzy logic model. However, they still may be increased and detailed in number by adding other related area-based ratios with various degrees. As are patient areas observed to be more dominant factor of efficiency, due to patient comfort and ease of operation, than circulation 


\begin{tabular}{|l|l|l|l|l|}
\hline Situation & $\begin{array}{l}\text { IF } \\
\text { Primary Area } \\
\text { per Bed }\end{array}$ & $\begin{array}{l}\text { AND } \\
\text { Circulation } \\
\text { Area per Bed }\end{array}$ & $\begin{array}{l}\text { THEN } \\
\text { Efficiency } \\
\text { is }\end{array}$ & COMMENT \\
\hline 1 & Low & Low & Low & Would expect inefficiency due to low primary area \\
\hline 2 & Low & Medium & Low & Would expect inefficiency due to low primary area \\
\hline 3 & Low & High & Low & Would expect inefficiency due to low primary area \\
\hline 4 & Medium & Low & Medium & Would expect efficiency due to low circulation \\
\hline 5 & Medium & Medium & Medium & Would expect efficiency due to high primary area \\
\hline 6 & Medium & High & Medium & Would expect efficiency due to high primary area \\
\hline 7 & High & Low & High & Would expect efficiency due to low circulation \\
\hline 8 & High & Medium & High & Would expect efficiency due to high primary area \\
\hline 9 & High & High & Medium & Would expect efficiency due to high primary area \\
\hline
\end{tabular}

Table 2. Fuzzy rules relating primary area per bed and circulation area per bed. areas, all possible fuzzy rules in the fuzzy set were to be employed to transform these inputs to corresponding output by taking the importance of the former into consideration. For example,

IF the primary area per bed is 'Low', and the circulation area per bed is 'Medium',

THEN the efficiency is Low'

IF the primary area per bed is 'Medium', and the circulation area per bed is 'High',

THEN the efficiency is 'Medium'

As fuzzy inferencing engine operators, min operator was employed for finding firing strength of each rule; max composition operator was employed for combining fuzzy output sets from each fired rule into a single fuzzy output set; and centroid method was employed for defuzzification.

\section{MODEL APPLICATION}

The developed fuzzy logic algorithm was applied to classify efficiency of existing nursing unit floors mentioned previously; and to compare the degree of efficiency among them. Taking derived ratios of the samples into consideration, the prediction of the efficiency values by the fuzzy model is summarized in Table 3.

The fuzzy subsets for the input and output variables are shown in Figure 6. According to Figure $\mathbf{6 c}$, one could see in which subset the efficiency value predicted by the fuzzy model falls into. For example, while Sample 05 was belonging to low efficiency with the value of 0.163 , Sample 12 was to medium efficiency with the value of 0.500 (Table 3). We may classify the efficiency values predicted by the fuzzy model into three groups as: Low Efficiency group where the rate is less than 0.25; Normal Efficiency class where the rate is in between 0.25 and 0.75 ; and High Efficiency group where the rate is greater than 0.75 . Although one may also further divide the Normal Efficiency range into subsets as Low-Medium and MediumHigh, from a practical point of view, in this study, we prefer to classify the results according to 3 major categories of Low, Medium and High efficiency. Figure 7 shows the distribution of predicted efficiency values for the existing sample hospitals. According to Figure 7, most of the existing nursing floors were belonging to a class of medium efficiency ranging from 0.324 to 0.500 . There were 6 out of 15 included in a class of low efficiency, while the rest in a class of medium one. These results imply that none of the hospitals are in overall agreement with current spatial requirements 
Figure 7. Distribution of efficiency for existing sample hospitals.

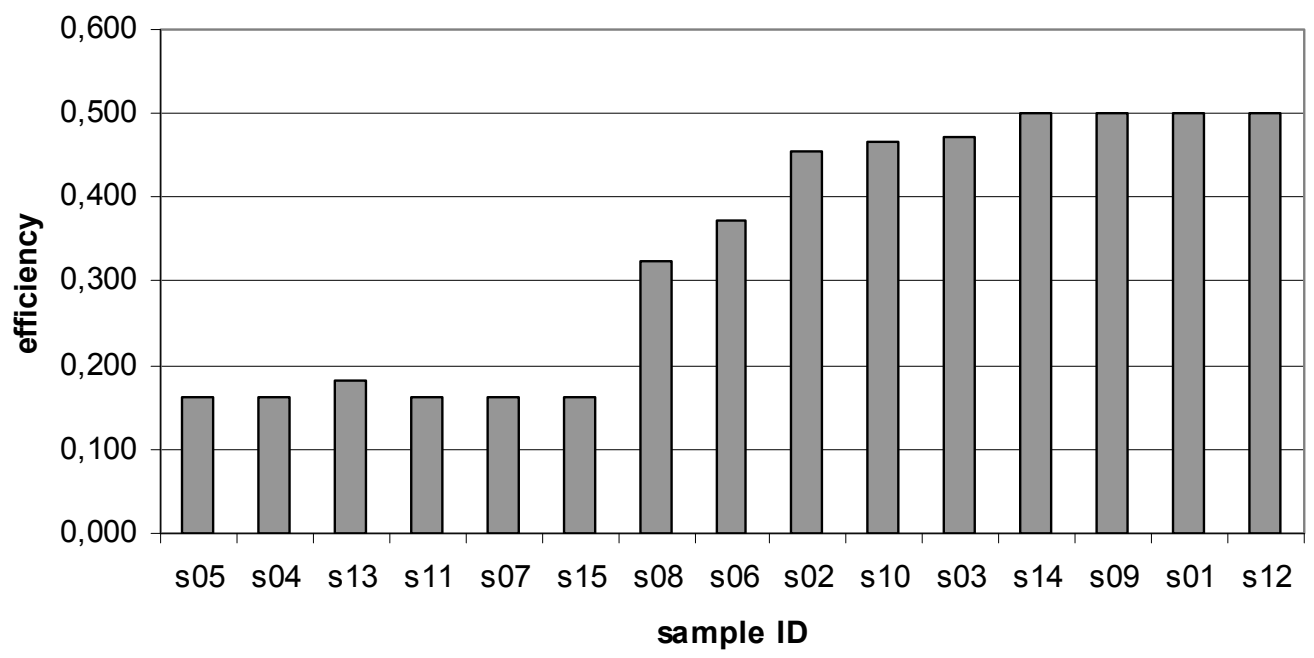

\begin{tabular}{|c|c|c|c|c|c|}
\hline $\begin{array}{l}\text { Sample } \\
\text { ID }\end{array}$ & $\begin{array}{l}\text { Primary } \\
\text { Area } \\
\text { Per Bed } \\
\left(\mathrm{m}^{2}\right)\end{array}$ & $\begin{array}{l}\text { Circulation } \\
\text { area Per } \\
\text { Bed }\left(\mathrm{m}^{2}\right)\end{array}$ & $\begin{array}{l}\text { Recommended } \\
\text { Circulation } \\
\text { Area per Bed } \\
(20 \%)\end{array}$ & Efficiency & COMMENT \\
\hline S05 & 6.30 & 5.60 & 1.26 & 0.163 & $\begin{array}{l}\text { Primary Area per bed provides insufficient space } \\
\text { around the bed (Area of bed }=2.235 \mathrm{~m}^{2} \text { alone which } \\
\text { leaves } 4.07 \mathrm{~m}^{2} \text { space around the bed). Circulation area } \\
\text { per bed unrealistically high. }\end{array}$ \\
\hline S04 & 6.90 & 4.40 & 1.38 & 0.163 & $\begin{array}{l}\text { Primary Area per bed provides insufficient } \\
\text { space around the bed. Circulation area per bed } \\
\text { unrealistically high. }\end{array}$ \\
\hline S13 & 7.00 & 2.30 & 1.40 & 0.181 & $\begin{array}{l}\text { Primary Area per bed provides insufficient space } \\
\text { around the bed. Circulation area per bed rather high. }\end{array}$ \\
\hline S11 & 8.00 & 11.70 & 1.60 & 0.163 & $\begin{array}{l}\text { Primary Area per bed provides insufficient } \\
\text { space around the bed. Circulation area per bed } \\
\text { unrealistically high. }\end{array}$ \\
\hline S07 & 8.10 & 7.00 & 1.62 & 0.163 & $\begin{array}{l}\text { Primary Area per bed provides insufficient } \\
\text { space around the bed. Circulation area per bed } \\
\text { unrealistically high. }\end{array}$ \\
\hline S15 & 9.00 & 26.90 & 1.80 & 0.163 & Circulation area per bed unrealistically high. \\
\hline S08 & 9.80 & 8.20 & 1.96 & 0.324 & Circulation area per bed unrealistically high. \\
\hline S06 & 10.20 & 9.40 & 2.04 & 0.372 & Circulation area per bed unrealistically high. \\
\hline S02 & 11.30 & 5.50 & 2.26 & 0.455 & Circulation area per bed rather high. \\
\hline S10 & 11.50 & 11.60 & 2.30 & 0.465 & Circulation area per bed unrealistically high. \\
\hline S03 & 11.70 & 6.20 & 2.34 & 0.473 & Circulation area per bed rather high. \\
\hline S14 & 13.10 & 26.00 & 2.62 & 0.500 & $\begin{array}{l}\text { Primary Area per bed provides relatively sufficient } \\
\text { space around the bed. Circulation area per bed } \\
\text { unrealistically high. }\end{array}$ \\
\hline S09 & 13.30 & 11.40 & 2.66 & 0.500 & $\begin{array}{l}\text { Primary Area per bed provides relatively sufficient } \\
\text { space around the bed. Circulation area per bed } \\
\text { unrealistically high. }\end{array}$ \\
\hline S01 & 13.50 & 8.40 & 2.70 & 0.500 & $\begin{array}{l}\text { Primary Area per bed provides relatively sufficient } \\
\text { space around the bed. Circulation area per bed } \\
\text { rather high. }\end{array}$ \\
\hline S12 & 14.70 & 17.20 & 2.94 & 0.500 & $\begin{array}{l}\text { Primary Area per bed provides relatively sufficient } \\
\text { space around the bed. Circulation area per bed } \\
\text { unrealistically high. }\end{array}$ \\
\hline
\end{tabular}


and design criteria for nursing unit floors mentioned in literature (Catananti, 1998; NHS Estates, 2005).

Another is a distinct change observed in the degree of efficiency due to circulation areas despite a clue showing its low impact. In other words, efficiency for six samples, namely, S05, S04, S13, S11, S07, S15 with similar 'low' values of primary area per bed, as 6.3, 6.9, 7.00, 8.00, 8.10, 9.00 respectively, and providing insufficient space around bed, are expected to present similar low values. It increased for S13, however, and stayed at a higher level than others due to its lower value of circulation area per bed, although efficiency for S15 presented a relatively high value of primary area per bed. For all these samples circulation area per bed was unrealistically high. As can be explained in another example, a very high value of primary area per bed with a high level of circulation area per bed, for S12, resulted in a medium efficiency as a mid-value of 0.5 . When compared with the recommended values, circulation area per bed was rather or unrealistically high for each sample.

Though other area-based ratios as analogue indicators for measuring planimetric design efficiency were developed in a previous study by the first author (Kazanasmaz, 2005), and their distributions with their significance among plan types were analyzed, there were not any sufficient results showing classification of their efficiency. It was obvious in this study that fuzzy logic algorithm was satisfactorily formed a classification for this purpose. Resulted values then would be compared with each other and general design standards for hospitals.

\section{CONCLUDING REMARKS}

In this study, a fuzzy logic algorithm, as an alternative method, was offered to define reliable planimetric efficiency classes. Although the outcome was a planimetric efficiency statistic by which various hospitals might be compared, the focus was based much on the methodological view. The fuzzy logic model was then constructed in accordance with expert opinions, general norms, guidelines and previous studies; and data obtained from existing sample hospitals in Turkey were reliably employed in the fuzzy model. The classification of efficiency was resulted satisfactorily in terms of comparing hospitals, since the application of concepts from the United States (AIA Guidelines for Design and Construction of Hospital and Healthcare Facilities) was appropriate.

Conclusions to be derived from the study were viewed from two distinct but interrelated standpoints: Those about the investigation as one dealing with methodology; and those about the investigation as dealing with planimetric efficiency of nursing unit floors in hospitals. First, for the sample from Turkey, application of guidelines mentioned in the literature (The American Institute of Architects, 1997; NHS Estates 2005) was not appropriate in general. Primary area per bed for all samples was lower than area mentioned in guidelines, while circulations area per bed for all samples was higher than recommended values in standards. As is the case for the need of efficient layouts in nursing floors as mentioned in Introduction, the main question was to define analogue indicators for planimetric efficiency for hospitals. Here, primary and circulation areas per bed were defined in reference of specific norms, guidelines and previous studies. The dominant importance of primary areas over circulation areas were taken into consideration in the study. However, the impact of 
circulation areas on planimetric efficiency was not eliminated. An effort was spent on constructing a new methodology for the investigation by using an intelligence method called fuzzy logic algorithm. Since this algorithm has been widely used in many studies for different engineering applications (Sen, 1998; Sivanandam et al., 2007; Akkurt et al. 2004; Saltan et al., 2007; Tayfur et al., 2003; Tayfur, 2006) and not used in architecture, this trial study attempt to put forth this methodology in the field of architectural researches. It is clear that engineering differs from architectural design both in practice and completed outcomes; however, a few trial applications for this model in the field of architecture (Çiftcioğlu, 2003; Vakili-Ardebili and Boussabaine, 2007), depicts such a clue that it may be applicable also in architecture and it may define design efficiency classes which are very likely to be correct. In addition, the lack of application of the algorithm particularly in hospital design may be to do with the evolution of the nursing unit. As are noted various results in Application Part, it was considered that, overall, fuzzy logic model constructed here was, to all intents and purposes, both a viable and an appropriate one in terms of developing a classification among planimetric efficiency of hospitals in regard to their nursing unit floors. The utility of this model is in the capability to indicate boundaries of efficiency classes, and it is a time consuming and dependable process in providing feedback information for existing buildings. As the sample from Turkey was limited, authors did not seek to use metrics more easy to generalize, but explored the methodology in this study.

Researchers will benefit from this model in building evaluation processes by making comparisons. They may improve it with variables indicating spatial requirements and environmental requirements. Hospital designers may use this tool as an aid briefing in the design process by getting feedback information from evaluations and comparisons of existing buildings. Designers will use this model then in decision making processes. Hospital managers also will be aware of the efficiency of their hospitals to decide whether to renovate or to adapt existing hospitals to future developments.

Although the paper considers the efficiency of the nursing floor plan, the current concerns for the hospital planning and design introduced in recent period have included the environmental concerns and aesthetics to enhance the healing process. Consequently, the quality of hospital design has supported the users' satisfaction and patients' need (Millman and Smith, 2003; Kobus, 2000). In relation to these, it would also be worthwhile conducting more exhaustive studies on more representative samples by constructing fuzzy model with more variables in number regarding not only those aspects covered here, but also others of potential relevance, such as recent considerations in hospital design, as mentioned above. Such aspects might be, for example, compactness efficiency in relation to heat loss capacity, construction efficiency in terms of cost-based items, environmental efficiency in terms of thermal, visual and ventilating aspects and overall design efficiency including more area-based ratios, demand of patients, and their satisfaction. Although this study basically focused on planimetric efficiency, other important design considerations such as those related with 'sections' to avoid the problems of "deep planning" and such environmental requirements, together with some factors of design efficiency such as spatial quality, planimetric configurations, and cost related items, would be investigated in further research. Other future studies might concentrate on different types of buildings in order to 
investigate their overall design efficiency including those factors by other specific analogue indicators.

\section{REFERENCES}

AKKURT, S., TAYFUR, G., CAN, S. (2004) Fuzzy logic model for the prediction of cement compressive strength. Cement and Concrete Research, 34 (8); 1429-33.

BOBROW, M., THOMAS, J. (2000) Inpatient Care Facilities, in S. Kliment (ed), Building Type Basics for Healthcare Facilities, Canada: John Wiley and Sons; 131-92.

CATANANTI, C., DAMIANI, G., CAPELLI, G. (1997) Buildings for Health Care Facilities, (Printed Version) v: 3.

CHAUDHURY, H., MAHMOOD, A., VALENTE, M. (2003) The Use of Single Patient Rooms vs. Multiple Occupancy Rooms in Acute Care Environments, A Review and Analysis of the Literature submitted to The Coalition for Health Environments Research. http://www.aia. org; accessed June 2007.

CHAND, S (2002) Architecture And The Hospital, Architecture Australia, 91 (4); 64-5.

COX, A, GRAVES, P. (1981) Design for Health Care, Butterworths, London.

ÇİFTÇİĞLU, Ö. (2003) Design Enhancement by Fuzzy Logic in Architecture, The IEEE International Conference on Fuzzy Systems.

HARDY, O.B., LAMMMERS, L.P. (1986) Design Efficiency: key to construction cost savings, Hospitals The Planning and Design Process, Aspen Publishers, USA.

JAMES, W.P., TATTON-BROWN, W. (1986) Hospital Design and Development,Butterworth Architecture. Sevenoaks, Kent.

JANTZEN, J. (1999) Design of fuzzy controllers, Technical Report, No: 98E864, Department of Automation, Technical University of Denmark.

KAZANASMAZ, T. (2005) An Investigation on the Planimetric Design Efficiency of Inpatient Departments in Healthcare Facilities, PhD.Thesis, Department of Architecture, Middle East Technical University, Ankara.

KAZANASMAZ, T. (2009) The Impact of Planimetric Configuration on Structurally Damaged Residential Buildings, Architectural Science Review, 52 (1): 54-70.

KIM, D. (2001) Specialized Knowledge Roles and the Professional Status of Healthcare Architects, Ph.D. Thesis., University of Texas, USA.

KOBUS, R.L. (2000) Perspective, S. Kliment, ed., Building type Basics for Healthcare Facilities, John Wiley and Sons, Canada; 1-8.

MILLER, R.L., SWENSSON, E.S. (2005) Hospital and Healthcare Facility Design, McGraw-Hill Inc., Hong Kong.

MILLMAN, J., SMITH, M. (2003) Hospital Design, Business Briefing: Hospital Engineering and Facilities Management; 50-3.

NEUFERT, E. (2000) Architect's Data (3rd edition), Wiley-Blackwell, GB. 
NHS Estates (2005) Ward Layouts with single rooms and space for flexibility, Gateway Ref: 4219.http:/ / www.sykehusplan.org. accessed 13.02.2008.

SALTAN, M., SALTAN, S., ŞAHİNER, A. (2007) Fuzzy logic modeling of deflection behavior against dynamic loading in flexible pavements, Construction and Building Materials (21); 1406-14.

SEN, Z. (1998) Fuzzy algorithm for estimation of solar irradiation from sunshine duration, Solar Energy, 63 (1); 39-49.

SIVANANDAM. S.N., SUMATHI, S., DEEPA, S.N. (2007) Introduction to Fuzzy Logic using MATLAB, Springer-Verlag, Berlin Heidelberg.

TAYFUR, G., ÖZDEMİR, S, SINGH, V.P. (2003) Fuzzy Logic algorithm for runoff-induced sediment transport from bare soil surfaces, Advances in Water Resources, 26); 1249-56.

TAYFUR, G. (2006) Fuzzy, ANN, and regression models to predict longitudinal dispersion coefficient in natural streams, Nordic Hydrology, 37 (2); 143-64.

The American Institute of Architects (1997) Guidelines for Design and Construction of Hospital and Healthcare Facilities, The American Institute of Architects Press. Washington DC, http:/ / www.aia.org. accessed 07.06.2007.

TRADEWELL, G.B. (1993) Contemporary nursing unit configuration, D. K. Hamilton, ed., Unit 2000: Patient Beds for the Future, A nursing unit design symposium, Watkins Carter Hamilton Architects, Inc., Houston; 191-215.

VAKILI-ARDEBILI, A., BOUSSABAINE, A.H. (2007) Application of fuzzy techniques to develop an assessment framework for building design eco-drivers, Building and Environment (42) 11; 3785-800.

VOORDT, T.J.M., VRIELINK, D., WEGEN, H.B.R. (1997) Comparative floor plan analysis in programming and architectural design, Design Studies (18); 67-88.

Alınd1: 02.07.2009. Son Metin: 04.01.2012

Anahtar Sözcükler: bulanık mantık; planimetrik verimlilik; hasta bakım katlarl; hastaneler; mimarlık.

\section{HASTA BAKIM KATLARININ PLANIMETRİK VERIMLİLİĞİ İÇINN SINIFLANDIRMALAR}

Bu çalışma, Türkiye'deki 15 Devlet Hastanesine ait 'Hasta Bakım Üniteleri' verilerini kullanarak, mimarlık alanında oldukça yeni olan Bulanık Mantık metodu ile verimlilik tahmini yapmakta; bu çerçevede bulanık mantık algoritması geliştirerek, Türkiye' de örnek olarak seçilen kamu hastanelerinin plan (planimetric) tasarım verimliliği için sınıflandırmalar geliştirmeye çalışmaktadır. Hasta bakım ve tedavi ünitelerinin kat planlarından hasta kullanım alanları ve dolaşım alanları elde edilerek bulanık mantık modeli alt kümeleri için üyelik fonksiyonları oluşturulmuştur. 'Mamdanni' kural sistemi, kuralların ağırlıklarını hesaplamada 'min' fonksiyonu, ve 'max' kompozisyonu ve 'centroid' metodu da bulanık işlemcisi için kullanılmıştır. Girdi değişkenleri olarak hasta kullanım alanları ve dolaşım alanları modellenmiştir. Girdi değişkenleri ile çıktı değişkeni olan tasarım 
verimliliği arasındaki ilişkiler bulanık mantık kuralları ile ortaya çıkarılmıştır. Varolan hasta bakım ünitelerini incelemek için, verimlilik çıktı değerleri modelden elde edilmiștir. Genel tasarım normları, tasarım ölçütleri ve önceki çalışmalar ışı̆̆ı̆ da ve de bu model aracılığıyla verimlilik sınıfları oluşturulmuştur. Modelde test edilen 15 hastane kat planından altısının düşük verimli sınıf içinde, dokuzunun ise orta verimli sınıf içinde olduğu görülmüştür. Hiçbiri güncel standartlara ve gereksinimlere uygun değildir. $\mathrm{Bu}$ çalışmada elde edilen modelin faydası, verimlilik sınıflarının sınır değerlerini belirleme yeteneğinde olmasıdır. Hastanelerin karşılaştırılarak incelenmesi için oluşturulan verimlilik sınıflandırılması başarı ile sonuçlanmıştır. Hastane tasarımcıları ve yöneticileri, mevcut hastanelerin değerlendirmesini ve karşılaştırmaları yapabilmek için bu çalışmadan geribildirim yoluyla bilgi edinebilir. Sonuç olarak, ilgili binalar hakkında karar verme aşmasında(örneğin binanın iyileştirme ihtiyacının olup olmadığı, yeni mekanlara gerek duyulup duyulmadığı gibi) bu modelden faydalanabilirler.

TUĞÇE KAZANASMAZ; B.Arch., M.Arch., Ph.D.

Turkey. Holds a Ph.D. in Building Science from Middle East Technical University (METU), where she received her Master's and Bachelor's degrees in Architecture. Practiced as an architect both in Ankara and İzmir for three years. Her research fields are design efficiency of healthcare buildings; architectural lighting; building performance, and energy efficient design. Currently instructor in the Department of Architecture in İzmir Institute of Technology, tugcekazanasmaz@iyte.edu.tr

GÖKMEN TAYFUR; B.Arch., M.S.CE, M.S., Ph.D.

He Holds a Ph.D. and MS from University of California, Davis (US); and a Master's and Bachelor's degree of Civil Engineering in İstanbul Technical University (Turkey). His research fields are overland flows; channel flows; rainfall-runoff induced erosion/sediment transport; chemical transport in saturated and unsaturated zone; chemical transport by surface flows; GIS applications for hydrological watershed management; snowmelt; application of fuzzy logic. Currently professor in the Department of Civil Engineering, İzmir Institute of Technology.gokmentayfur@iyte.edu.t 